\title{
An Exploration of Video Game Construction and Student Learning
}

\author{
Kandise Salerno \\ University of Alberta \\ 551 Education South \\ Canada \\ kperry@ualberta.ca
}

\begin{abstract}
Video game construction in school environments is an emerging field of study. The National Media Consortium (NMC) suggests that playing and designing video games will become an important use of technology for kindergarten to grade twelve environments in the next two to three years. Researchers are beginning to suggest that constructing video games has the potential to transform the learner (Kafai, Ching \& Marshall, 1997; Kafai \& Ching, 2001; Peppler \& Kafai, 2007; Salen, 2007; Squire, 2006), through higher-level thinking (Salen, 2007), analytic and conceptual thinking (Clark \& Sheridan, 2010), reflection and evaluation (Dickey, 2006) and a context to learn about and with technology (Kafai, Ching \& Marshall, 1997). This literature review will further illuminate the research surrounding video game construction and some of the potential roadblocks that might exist for educators looking to integrate these technologies into the school environment.
\end{abstract}

Keywords: Video game construction, constructionism, technology integration, maker movement, 21st century learning

\section{The Changing Winds of Technology Integration}

Today is a windy day. The aspens in my backyard sway to and fro as the winds pound their leaves and shake their branches. It is an alluring sight to watch these trees tremble from the chilly winds that traverse through their leaves, leaving an identifiable difference on their majestic presence. In watching these gusting winds and awaiting the forthcoming storm that only the wind can beckon, I wonder about the changing winds that are metaphorically situated in our own lives. Change seems to be a rampant entity in how we comprise our lives in the $21^{\text {st }}$ century. Although there are many gusting winds that traverse this change, digital technologies seem to be one of more forceful entities that have altered the very fabric of our lives. Although some may question the origin of this force, whether it is bred from the very existence of digital technology or directly correlated with the demand of the user, the force of this change is unequivocal.

In digging deeper into the rampant change associated with digital technologies, there is no question that school environments have weathered an insurmountable amount of change. In fact, some have identified technology integration into school environments as a wicked problem (Koehler \& Mishra, 2008). Rittel and Webber (1973) identify a wicked problem as one that is potentially impossible to solve, incredibly complex and if a solution is found, it is likely that it will lead to other problems. The historical narratives that echo throughout the halls of many schools would further illuminate this wicked 
problem, whereas technologies such as B.F. Skinners teaching machine introduced in the late 1950s or the newly introduced interactive whiteboard have struggled to become transformative entities in the classroom.

The National Media Consortium (NMC) also reaffirms the difficulties associated with digital technologies in both $\mathrm{K}-12$ and higher education settings. The NMC publishes a yearly report entitled, the Horizon Report, which identifies and explores the key trends, challenges and important developments that are likely to transpire over the next five years regarding technology integration. Interestingly, the 2014 edition of the K-12 report identifies the continued relevancy of formal education as one particular wicked problem.

This report suggests that "stakeholders and administrators might seriously consider what schools can provide that cannot be replicated by other sources" (NMC, 2014, p. 30). The NMC suggests that soft skills, such as work ethic, a sense of grit, and social skills need to become a more recognized and pivotal component of formal education. As a wicked problem, the complexity associated with maintaining the relevancy of formal education is staggering, but the Horizon Report also illuminates technologies that might support this transition.

The NMC identifies video games and gamification as one important development that will likely impact the K-12 learning environment in the next two to three years. In fact, there is affirmative research that suggests both playing and constructing video games can facilitate a transformative learning experience for students, in which they achieve higher-level thinking (Salen, 2007), analytic and conceptual thinking (Clark \& Sheridan, 2010), reflection and evaluation (Dickey, 2006) and a context to learn about and with technology (Kafai, Ching \& Marshall, 1997). When considering that for over $80 \%$ of students, video games play an integral role in their everyday lives (Beavis, Apperley, Bradford, O'Mara \& Walsh, 2009), it seems imperative that students have the opportunity to play and construct video games at school, notwithstanding that these video games also might respond to the wicked problem associated with maintaining the relevancy of formal education.

The purpose of this paper is situated in the NMC's outwardly perspective regarding the potential role video game construction offers to the $21^{\text {st }}$ century learner. This paper will explore the research that has emerged regarding video game construction and the potential merit it serves to the learner and the school environment.

\section{The Origins of Video Game Construction}

The maker movement or maker spaces have become an emerging trend in schools and libraries as a viable and promising application of digital technologies. Certainly video game construction is situated within this maker movement, which can be closely attributed to the work of Seymour Papert (1980) and his seminal research surrounding LOGO programming and constructionism. Papert came to understand that children think a great deal about their thinking, and "we can provide them materials to help them do it better" (Papert, 1980, p. 145). Papert (1980) understood that the computer allows, or "obliges the child to externalize intuitive expectations" and "computational ideas can be taken up as materials for the work of modeling intuitive knowledge" (p. 145).

In applying these maker technologies, children come to use them in ways that can differ from more behaviorist technologies, such as recent applications of the iPad or the interactive whiteboard. In fact, these constructionist technologies facilitate a tinkering or 
bricolage experience, where the object plays a central role for the bricoleur, as "they are constantly musing over objects, engaged precisely with what is not themselves, in order to see what possibilities the objects have to offer" (Crotty, 1998, p. 50). For students immersed in video game construction, bricolage enables gamers to isolate and correct the bugs that keep the game from working, and consequently level up in the video game through this, "use what you got, improvise, and make do" (Papert, 1993, p. 144) philosophy.

The maker movement and the application of a constructionist learning paradigm begins to respond to some of the issues the NMC identifies in the Horizon Report. Providing students with a hands-on, learning by doing approach not only allows them to further formulate their ideas through authentic and rigorous learning experiences, but it also facilitates the application of their soft skills. While children are constructing a video game, it seems apparent that they would need to collaborate with others, organize their ideas and put forth a considerable amount of effort to create a successful game. Jenkins (2006) connects with the maker movement, suggesting digital learners demand a more participatory experience that allows them to share, modify and construct new perceptions of the world through the use of varying technologies.

A participatory culture has relatively low barriers to artistic expression and civic engagement, strong support for creating and sharing one's creations, and some type of informal mentorship whereby what is known by the most experienced is passed along to novices. A participatory culture is also one in which members believe their contributions matter, and feel some degree of social connection with another. (Jenkins, 2006, p. 3)

\section{Constructionism in the Participatory Culture}

The Computer Clubhouse (Kafai et al., 2009) is an excellent, living example of students immersed in video game construction. This clubhouse is an after school program that facilitates game construction experiences for thousands of adolescents around the world, while meeting the creative interests of adolescents. The Computer Clubhouse not only demonstrates the interest adolescents have regarding video game construction, but also the potential merit game construction has for the educational community. In fact, Kafai and Ching (2001), Peppler and Kafai (2007), Prensky (2007), Salen (2007) and Squire (2006) question if the play experience derived from playing video games is enough to meet the participatory needs of $21^{\text {st }}$ century learners. Peppler and Kafai (2007) suggest the old "sender-receiver model" (p. 151) does not support the production and design demands of students.

Creative production, or learning-by doing, is in many regards at the epicenter of the participatory culture. Peppler and Kafai (2007) present three key arguments for creative production in school environments.

1. Creative production can be seen as a new emphasis on critical writing of texts, broadly defined as written texts, software programs, media images, oral discussion or other media objects.

2. Youth need to move beyond participation via blogging and game playing to create their own video games, media art or graphical user interfaces.

3. Having an audience motivates youth to produce creative work. (pp. 151-152) 
Modern, digital technologies such as playing video games offer a wide range of possibilities for learners; however learners must also be equipped with experiences that facilitate some level of production and modification. Squire (2008) would attest, "the focus should be less on content and more on designing experiences to simulate new ways of thinking, acting and being in the world" (pp. 14-15). Student-based video game construction is one potential response to meeting the needs of the participatory culture.

\section{The Potential of Video Game Construction}

Although Papert (1980) began his work with LOGO programming well over a half a century ago, his philosophy of constructionism has only begun to be fully recognized in education and research. Salen (2007) found game making to be well suited to encouraging "meta-level reflection on the skills and processes that designer-players use in building such systems, be the games or communities of practice" (p. 319). She also found that programs such as Scratch teach "procedural thinking, problem solving and logic by learning to program" (Salen, 2007, p. 303). Clark and Sheridan (2010) further explore the cognitive benefits of game construction, "as designing games involves analytic and conceptual thinking and problem solving in addition to the traditional skills involved" (p. 127). Furthermore, Kafai and Ching (2001) found student-based designed software "fosters student experiences of science questions and ideas in a concrete computational artifact" (p. 324).

Gaydos and Squire (2012) suggest that in most school activities "one is not encouraged to express difficulty, in game-based learning spaces, acknowledging challenges can be a sign of expertise" (p. 836). Gee (2007) further identifies that good games are in fact pleasantly frustrating, "which is at the outer edge but within their 'regime of competence.' That these challenges feel hard, but doable" (p. 36).

Beyond the cognitive benefits of student-based game construction, Salen (2007) found that student designed games facilitate a greater degree of risk taking and learning in low risk settings. Robertson and Good (2005) write about the positive impact student-based game design has on written literacy, "creating stories in a non-textual medium can act as a bridge to written literacy" (p. 44). Dickey (2006) further highlights the benefits of game design, as it facilitates a positive narrative writing experience that supports reflection, evaluation, illustration, exemplification and inquiry. This non-traditional narrative experience not only provides "insight into how and why carrying the narrative through an activity might enhance learning" but also "how narrative may be interwoven to provide motivation and cognitive scaffolding" (Dickey, 2006, p. 257). Dickey (2006) further elaborates that game design is one promising model that demonstrates how to develop an interactive learning environment.

Kafai et al., (1997) illustrate the significance of student-based game design through "a context to learn about and with technology" (p. 122). Notably, student-based game design has the potential to offer a more dynamic epistemic frame/projective stance, or an island of expertise (Shaffer, 2006) as the student is not only playing a game but also developing an expertise of the content, experiencing the role of game designer, and developing an understanding of the technology. Apperley and Beavis (2011) found the process of game design "allows the student to experience the negotiation between their desired performance for the game and the technical affordances available to them" ( $p$. 138). This negotiation allows students to understand diegetic actions (performed by the 
hardware and software) and non-diegetic actions (outside the game world), in which what they have control over, and what is a controlled entity in the game world.

Research surrounding student-based game design has emerged in a relatively positive light, however some are hesitant regarding the complexity and purpose it serves to the student learner.

Prensky (2008) notes that game design is a difficult undertaking. He cites Will Wright, the creator of The Sims and Spore who notes, "creating a good game is hard enough; creating one based on educational content is even harder" (p. 1009). Lim (2008) further suggests the varying issues that can arise from incorporating game design into the classroom.

For example, due to a lack of time, inflexible time-table, and a highly structured, discipline-specific curriculum of the school, a computer game may be introduced for an hour on Monday, students may be allowed to explore the features of the game for an hour on Wednesday, they may get to play the game for an hour on Friday, and they are expected to reflect and discuss about the game the following Monday. (Lim, 2008, p. 1002)

Although Lim (2008) questions if it is indeed possible for students to construct a video game, the research community is fairly certain that technology and student ability are well versed in game construction (Baytak \& Land, 2011; Kafai et al., 1997; Kafai \& Ching, 2001; Papert, 1980, 1991; Peppler \& Kafai, 2007; Salen, 2007; Squire, 2006).

\section{Potential Roadblocks for Video Game Construction}

The NMC clearly notes that digital technologies are exceptionally difficult to integrate into the classroom, as both the teacher and student are characterized by different experiences and perceptions. Interpreting and understanding how these digital technologies can be used in the classroom can place a number of demands on the teacher (Borko, Whitcomb \& Liston, 2009; Doering, Scharber \& Veletsianos, 2009; Koehler \& Mishra, 2008, 2009). Part of these demands resides in the different goals, objectives and beliefs held by teachers (Koehler \& Mishra, 2008). Certainly, constructionism and maker technologies present a distinct division of perspective, as many teachers are framed through a more behavioristic learning tradition, while digital learners expect a more open-ended, participatory experience. For Papert (1993) he suggests that in a traditional learning environment, the teacher is the only active subject in the classroom, "as the teacher is in control and is therefore the one who needs skill; the learner simply has to obey instructions" (p. 83).

Niess et al. (2009) suggest the "major limitations of computer use in the coming decade are likely to be less a result of technological limitation than a result of limited human imagination and the constraints of old habits and social structure" (p. 6). Functional fixedness (German \& Barrett, 2005) represents one explanation regarding the restraints digital technologies and the perceived purpose they serve. Niess et al. (2009) emphasize this point through the interactions a group of math teachers experienced with a graphing calculator. They found their fixed, preconceived knowledge strongly regulated the use of the graphing calculator, as they primarily used it for "demonstration, verification and drill and practice techniques" (p. 6). Although the graphing calculator offers far greater potential to the learner beyond drill and practice experiences, as do most digital technologies, it is often used in ways that reflect the basic constructs of traditional technologies. 
Kynigos (2004) would further attest to the division of understanding through the introduction of black box, white box technology. Black box represents a prefabricated closed system artifact while white box represents a transparent, modifiable artifact. Niess et al. (2007) research surrounding the graphing calculator creates a strong correlation to a black box learning system, whereas digital learners generally demand a white box learning experience. Rice (2007) identifies that the release of classroom control and classroom structure is one of the main factors that restrict teachers from integrating white box technologies into the classroom.

Cuban, Kirkpatrick and Peck (2001) identify a high access, low use paradigm as one potential response to the problem of digital technology integration. Cuban et al. (2001) discuss a wide range of factors, including the rigid time structure found in the classroom, the defects associated with technology use, and the slow revolution that is often associated with educational technology implementation. Although each factor explains the stagnant development of digital technologies, the explanation surrounding the slow revolution seems to be the most poignant.

This explanation is anchored in the notion of lag time between the invention of a new technology and the adoption of innovations, and the slow spread of its virtues through the general population. Individuals and companies need decades to learn how to use and manage the new technology. (Cuban et al., 2001, p. 826)

This slow revolution provides two important indicators. First, black box learning systems establish a more congruent match between educators and their pedagogy. And second, educators are beginning to transition their practice from instructionist/behaviorist to constructionist, which means digital technologies have the potential to be a more congruent representation of classroom practice. As white box learning and a more aligned presence of digital technologies seems to be an imminent possibility in the near future, there is no question that video games "offers an enormous potential for their learning, both as children and as adults. (Prensky, 2007, p. 16)

\section{Forthcoming Research}

Video game construction programs continue to evolve into more accessible artifacts. In fact for some young gamers, they are able to program a video game before they can decode traditional text. Disney has identified the populatiry of game construction and has consequently developed a relatively new program that allows young gamers to actively play and construct games with relative ease. The video game is called, Infinity, and it hosts a toy box component in which the gamers have the opportunity to use "landscapes, buildings, vehicles, characters and other objects from the Disney universe" (Schmidt, 2013). In essence, young gamers can reconstruct the Disney worlds they so aptly understand, while building and sharing with their virtual friends.

The Infinity game program has become a popular artifact for many young gamers, whereas it has sold over 3 million copies in less than a year (Handrahan, 2014). In commulating the popularity of this program and the little research that has explored the experiences of young gamers in desgining and programming video games, it is my intent to further research the experiences of young gamers interacting with the Infinity game program. 
This forthcoming researh project will be framed through the following questions: How do young gamers experience the Infinity video game program? How do they collaborate with each other? What forms of video games do they construct? How do they level-up and have an epic win in their own game world? How do these experiences inform school library programs and the role of the teacher-librarian? How can these game construction programs be integrated into school library programs?

This research project will begin to identity how these programs can be integrated into school library spaces, particularly for the elementary students. Integrating video game construction into the school library or classroom may further support teachers as they respond to the wicked problem of technology integration. Video game construction seems to respond to the digital needs of students while effectively integrating the use technology into learning spaces.

\section{References}

Apperley, T., \& Beavis, C. (2011). Literacy into action: digital games as action and text in the English and literacy classroom. Pedagogies: An International Journal, 6(2), 130143. doi: $10.1080 / 1554480 X .2011 .554620$

Baytak, A., \& Land, S. M. (2011). An investigation of the artifacts and process of constructing computers games about environmental science in a fifth grade classroom. Educational Technology, Research and Development, 59(6), 765-782. doi:10.1007/s11423-0109184-z

Beavis, C., Apperley, T., Bradford, C., O’Mara, J., \& Walsh, C. (2009). Literacy in the digital age: Learning from computer games. English in Education, 43(2), 162-175. doi: 10.1111/j.1754-8845.2009.01035.x

Borko, H., Whitcomb, J., \& Liston, D. (2009). Wicked problems and other thoughts on issues of technology and teacher learning. Journal of Teacher Education, 60(1), 3-7. doi: 10.1177/0022487108328488

Chee, Y. S., \& Tan, K. C. D. (2012). Becoming chemists through game-based inquiry learning: The case of "legends of alkhimia". Electronic Journal of e-Learning, 10(2), 185-198. Retrieved from www.ejel.otg

Clark, K., \& Sheridan, K. (2010). Game design through mentoring and collaboration. Journal of Educational Multimedia and Hypermedia, 19(2), 125-145. Retrieved from http://www.editlib.org/p/33097

Crotty, M. (1998). The foundations of social research: Meaning and perspective in the research process. Thousand Oaks, California: Sage Publications.

Cuban, L., Kirkpatrick, H., \& Peck, C. (2001). High access and low use of technologies in high school classrooms: Explaining an apparent paradox. American Educational Research Journal. 38(4), 813-834. doi: 10.3102/00028312038004813 
Dickey, M. D. (2006). Game design narrative for learning: Appropriating adventure game design narrative devices and techniques for the design of interactive learning environments. Educational Technology Research and Development, 54(3), 245-263. doi: 10.1007/s11423-006-8806-y

Doering, A., Scharber, C., Miller, C., \& Veletsianos, G. (2009). GeoThentic: Designing and assessing with technology, pedagogy, and content knowledge. Contemporary Issues in Technology and Teacher Education, 9(3), 316-336. Retrieved from http://www.editlib.org/p/29379.

Egenfeldt-Nielsen, S., Smith, J. H., \& Tosca, S. P. (2012). Understanding video games: The essential introduction. New York: Routledge.

Egenfeldt-Nielsen, S. (2007). Educational potential of computer games. London: Continuum, 2007.

Foster, A. (2008). Games and motivation to learn science: Personal identity, applicability, relevance and meaningfulness. Journal of Interactive Learning Research, 19(4), 597614. Retrieved from http://www.aace.org/pubs/jilr/

Gaydos, M. J., \& Squire, K. D. (2012). Role playing games for scientific citizenship. Cultural Studies of Science Education, 7(4), 821-844. doi: 10.1007/s11422-0129414-2

Gee, J. P. (2005). Learning by design: Good video games as learning machines. E-Learning, 2(1), 5-16.

Gee, J. P. (2007). Good video games +good learning. New York: Peter Lang Publishing.

German, T. P., \& Barrett, H. C. (2005). Functional fixedness in a technologically sparse culture. Psychological Science, 16(1), 1-5. doi:10.2307/40064063

Handrahan, H. (2014, January 20). Disney Infinity sells 3 million starter packs. [Web log post]. Retrieved from http://www.gamesindustry.biz/articles/2014-01-20-disney-infinitysells-3-million-starter-packs

Jenkins, H. (2006). Convergence culture: Where old and new media collide. New York: New York University Press.

Kafai, Y. B., \& Ching, C. C. (2001). Affordances of collaborative software design planning for elementary students' science talk. The Journal of the Learning Sciences, 10(3), 323-363. doi: $10.2307 / 1466754$

Kafai, Y. B., Ching, C. C., \& Marshall, S. (1997). Children as designers of educational multimedia software. Computers \& Education, 29(2/3), 117-126. doi: 10.1016/S03601315(97)00036-5

Kynigos, C. (2004). A "black-and-white box" approach to user empowerment with component computing. Interactive Learning Environments, 12(1), 27-71. doi: $10.1080 / 1049482042000300896$ 
Koehler, M. J., \& Mishra, P. (2008). Introducing TPCK. In The AACTE Committee on Innovation and Technology, M. Herring, P. Mishra \& M, Koehler (Eds.) Handbook of technological pedagogical content knowledge for educators (pp. 3-30). New York, NY: Routledge.

Koehler, M. J., \& Mishra, P. (2009). What is technological pedagogical content knowledge? Contemporary Issues in Technology and Teacher Education, 9(1), 60-70. Retrieved from http://www.aace.org/pubs/cite/

Lim, C. P. (2008). Spirit of the game: Empowering students as designers in schools? British Journal of Educational Technology, 39(6), 996-1003. doi: 10.1111/j.14678535.2008.00823_1.x

McGonigal, J. (2011). Reality is broken: Why games make us better and how they can change the world. New York, NY: The Penguin Press.

MacLaurin, M. (2011). The design of Kodu: A tiny visual programming language for children on the Xbox 360. Proceedings of the 38th annual ACM SIGPLAN-SIGACT symposium on principles of programming languages, Austin, USA, 241-246. doi: $10.1145 / 1926385.1926413$

Miller, L. D., Shell, D., Khandaker, N., \& Soh, L. (2011). Teaching using computer games. Journal of Educational Technology Systems, 39(3), 321-343. Retrieved from http://www.baywood.com/journals

National Media Consortium (2014). NMC horizon report $2014 \mathrm{~K}-12$ edition. Retrived from http://cdn.nmc.org/media/2014-nmc-horizon-report-k12-EN.pdf

Niess, M. L., Ronau, R. N., Shafer, K. G., Driskell, S. O., Harper, S. R., Johnston, C., ... Kersaint, G. (2009). Mathematics teacher TPACK standards and development model. Contemporary Issues in Technology and Teacher Education, 9(1), 4-24. Retrieved from http://www.aace.org/pubs/cite/

Papert, S. (1980). Mindstorms: Children, computers, and powerful ideas. New York: Basic Books.

Papert, S. (1991). Situating constructionism. In Harel, I. \& Papert, S. (Eds.) Constructionism (pp. 1-11). New York: Ablex Publishing Corporation

Papert, S. (1993). The children's machine: Rethinking school in the age of the computer. New York: Basic Books.

Peppler, K. A., \& Kafai, Y. B. (2007). From SuperGoo to scratch: Exploring creative digital media production in informal learning. Learning, Media and Technology, 32(2), 149-166. doi: 10.1080/17439880701343337

Prensky, M. (2007). Digital game-based learning. New York: Paragon House. 
Prensky, M. (2008). Students as designers and creators of educational computer games: Who else? British Journal of Educational Technology, 39(6), 1004-1019. doi:10.1111/j.1467-8535.2008.00823_2.x

Rice, J. (2007). Assessing higher order thinking in video games. Journal of Technology and Teacher Education, 15(1), 87-100. Retrieved from http://www.aace.org/pubs/jtate/

Rittel \& Webber (1973). Dilemmas in a general theory of planning. Policy Sciences. 4(2), 155-169. doi: 10.1007/BF01405730

Robertson, J., \& Good, J. (2005). Children's narrative development through computer game authoring. TechTrends: Linking Research \& Practice to Improve Learning, 49(5), 43-59. Retrieved from http://www.springer.com/education+\%26+language/learning $+\% 26+$ instruction/journ al/11528

Salen, K. (2007). Gaming literacies: A game design study in action. Journal of Educational Multimedia \& Hypermedia, 16(3), 301-322. Retrieved from http://www.aace.org/pubs/jemh/

Salen, K., \& Zimmerman, E., (2004). Rules of play: Game design fundamentals. Cambridge, Mass: MIT Press.

Schmidt, G. (2013, August 29). With Disney Infinity, players can explore a virtual toy box. The New York Times, p. B10.

Shaffer, D. W. (2006). Epistemic frames for epistemic games. Computers and Education, 46(3), 223-234. doi: 10.1016/j.compedu.2005.11.003

Squire, K. (2006). From content to context: Videogames as designed experience. Educational Researcher, 35(8), 19-29. doi: 10.3102/0013189X035008019

Squire, K. (2008). Video game-based learning: An emerging paradigm for instruction. Performance Improvement Quarterly, 26(1), 101-130. doi: 10.1002/piq.21139

Squire, K. (2011). Video games and learning: Teaching and participatory culture in the digital age. New York: Teachers College Press.

\section{Biographical Note}

Kandise Salerno is a PhD student at the University of Alberta, exploring the potential role video game construction programs have in school environments. She is also a technology coach with Edmonton Catholic Schools and collaborates with group of schools in Norway in exploring project based learning and educational technologies. She initiated one particular project, Oppfinnermesse i Nes which continues to play an important role in the community. 